\title{
Research on the Relationship between Data Empowerment and Service Innovation Capability of Logistics Platform Enterprise
}

\author{
Yuhua Zhang $\mathbb{D}^{1}$ and Mengdie $\mathrm{Hu}^{2}$ \\ ${ }^{1}$ Department of Business Administration, Guangzhou Huashang College, Guangzhou 510000, China \\ ${ }^{2}$ School of Business, Guangdong University of Foreign Studies, Guangzhou 510000, China \\ Correspondence should be addressed to Yuhua Zhang; zhyh58@163.com
}

Received 18 March 2021; Revised 24 April 2021; Accepted 15 May 2021; Published 28 May 2021

Academic Editor: Shianghau Wu

Copyright (c) 2021 Yuhua Zhang and Mengdie Hu. This is an open access article distributed under the Creative Commons Attribution License, which permits unrestricted use, distribution, and reproduction in any medium, provided the original work is properly cited.

\begin{abstract}
Based on the application of big data, this paper constructed a theoretical model focusing on the mechanism of data empowerment on the service innovation capability of logistics platform enterprises, with value cocreation as the mediating variable and environmental dynamism as the moderating variable. The research hypothesis was empirically tested based on the results obtained from the questionnaire survey. The results demonstrate that data empowerment can promote the value co-creation between logistics platform enterprises and users, and value co-creation is an important factor to promote the service innovation capability of logistics platform enterprises. Meanwhile, the moderating variable of environmental dynamism is found to inhibit the interaction between cooperation and service innovation capability. The findings expand the theoretical research on data empowerment and raise important inspiration for practical activities of logistics platform enterprises.
\end{abstract}

\section{Introduction}

The rapid development of the Internet and big data has made the service forms and applications of logistics enterprises more and more extensive, and various types of logistics platform enterprises are constantly emerging, i.e., intra-city freight logistics platform, vehicle-cargo matching bulk freight logistics platform, and highway-port logistics platform. Yunmanman, China's first freight dispatch platform enterprise that operates based on cloud computing, big data, mobile Internet, and artificial intelligence technologies, had developed into China's largest vehicle capacity scheduling platform, smart logistics information platform, and vehiclefree carrier in just 4 years. Platform enterprises extensively connect to bilateral (multilateral) users of the platform and establish an open innovation ecosystem relied on common infrastructure (e.g., platform architecture) [1]. A basic feature of platform enterprises is to reduce of transaction cost that prevents the value exchange among parties gathering together [2]. This improves the operating efficiency of participants and benefits both parties. Therefore, platform enterprises not only enable themselves to develop rapidly but also play a huge role in creating employment opportunities, innovating technological patterns, and benefiting the public.

The emergence of logistics platform enterprises has fundamentally solved the problems of fragmented traditional logistics resources, blocked transaction links, and low information concentration. In other words, it has completely changed the situation of "small, chaotic, and scattered" in traditional logistics industry in China, improving utilization rate of social resources and logistics operation efficiency, while reducing social logistics costs. However, it can also be seen that after several years of development, the intense competition among logistics platform enterprises generated by homogenization, weak overall innovation capabilities, and poor profitability has seriously hampered the healthy development of platform enterprises. Therefore, major logistics platform enterprises have been concerning on issues such as improving the service innovation capabilities of logistics platforms, obtaining more customer resources, and increasing market share. 
Big data changes the original production and operation patterns of enterprises, integrating and efficiently utilizing social resources, improving the efficiency of economic, and achieving sound and rapid economic development. Profoundly based on the progress of the Internet and big data, the developments of logistics platform enterprises provide timely and effective information for both parties in transaction, change the original logistics transaction patterns, and create higher value for logistics enterprises and customers. The application of big data provides efficient means for the development of logistics platform enterprises. Platform enterprises are committed to maximizing the sharing of information and resources, which is conducive to attracting more users and acquiring more data resources, thereby promoting the innovation and sustainable development of the platform-based logistics enterprises. The nature of the Internet platform is empowerment. In the future development of the logistics platform, data empowerment will become the main approach. Meanwhile, service innovation has added increasing significance and value to the development of logistics enterprises, and it is the main way for enterprises to achieve competitive advantages. Based on the existing problems of logistics platform enterprises and considering the importance of data empowerment and service innovation in logistics platforms, this research will clarify the mechanism and context of data empowerment to promote the improvement of service innovation capabilities for logistics platform enterprises, and it helps to provide practical reference for the sustainable and healthy development of logistics platform enterprises.

The research on data empowerment mainly focuses on business practice and the empowerment of social public affairs. For the empowerment of social public affairs, the research focuses more on the empowerment by digital technology for medical treatment and nursing of patients $[3,4]$, women's rights $[5,6]$, minors' health [7], social citizenship $[8,9]$, and the data enabling between teachers and students in the realization of classroom and distance education $[10,11]$. In recent years, due to the disruptive impact of data and data technology on business practices, data empowerment has attracted widespread attention in terms of patterns and means of empowerment. Moreover, research on capacity building and mechanism of data empowerment process, such as enterprise manufacturing transformation and upgrading, business model innovation, and value cocreation, has increased [12-14]. The research on service innovation capability focuses on the connotation and evaluation, the function mechanism, and the influence factors. For the connotation and influence factors, the research perspectives are based on supply chain integration [15-17], relationship network [18, 19], knowledge learning [20-22], and resource management [23]. For the evaluation of service innovation, the research measures are concerned from the aspect of capability characteristics [24] and comprehensive evaluation from the perspective of process $[25,26]$. For the function mechanism, the research focuses are regarding the mechanism of service innovation capability on enterprise performance and competitive advantage [27] and the mechanism of interaction orientation on innovation capability from three perspectives: value cocreation [28], absorptive capacity [29], and initiative improvement [30-32].

As of now, although there is enormous research focused on data empowerment as well as service innovation capability, very few studies explore the intersection and interaction of the two. Meanwhile, the practical activities which data empowers platform enterprise to promote innovation capability are very active, but there is scarce research on relationship between data empowerment and service innovation capability for platform enterprise. Therefore, this study aims to theoretically explain the relationship between data empowerment and service innovation capability, and using logistics platform enterprise as the research object, to study how data empowerment can promote the improvement of service innovation capability, thus provides theoretical guidance for the enterprise practice and provides a new starting point for the academic research on the data empowerment and innovation capability of platform enterprises.

In practice, the big data capability of platform enterprise based on Internet big data technology has an important impact on the improvement of service innovation capability. In addition, the realization of information communication between the buyer and the seller requires consumer to feed back demand information to enterprise actively, so as to realize the value of cocreation, and hence improve the service innovation capability of platform enterprise. However, platform enterprises, born in the Internet era, are bound to live in a highly variable environment. Therefore, environmental dynamism must be considered as an important factor to measure the improvement of service innovation capability of platform enterprises. This study will be carried out following the context of data empowerment, service innovation capability, value co-creation, and environmental dynamism.

\section{Theoretical Basis and Research Hypothesis}

2.1. Data Empowerment. In recent years, empowerment has received attention and emphasis in multiple professions and trades. In particular, data empowerment is applied more frequently in Internet industry, and the opinions, such as digital empowerment and Internet empowerment, have emerged, which indicate the rapid development of data applications. Empowerment is a purposeful and continuous process, emphasizing the concepts of group-centered and mutual respect, and concerns the participation of group members. By involving in these processes, members who lack equal and valuable resources could obtain and control these resources [33]. Empowerment is mainly classified into structural empowerment, psychological empowerment, and resource empowerment, and some scholars have claimed that structural empowerment and psychological empowerment do not truly reflect the connotation of empowerment. Therefore, the focus on the research of resource empowerment has been raised by more and more researchers. In the era of big data, the core function of resource empowerment is gradually reflected in data empowerment. Data 
empowerment is a process of realizing the value in which a specific system innovates the application scenarios of data and applies skills and methods to gain or improve the overall capability of the system. The realization of data empowerment depends on the enterprises' capabilities of information collection, processing, transmission, and storage. By improving these capabilities, enterprises can realize data potential to a greater extent, integrate corporate resources efficiently to better cater customer needs, promote the value of data, and improve corporate performance. Lenka et al. [14] classified data capabilities into intelligence capabilities, connection capabilities, and analysis capabilities. Intelligence capabilities represent hardware configuration capabilities and intelligence collection capabilities. Besides, connection capabilities represent information transmission, processing capabilities, and connectivity capabilities among other smart products. Analysis capabilities are the ability to transform the existing data into valuable insights and feasible instructions for enterprises.

\subsection{Data Empowerment and Service Innovation Capability.} With the continuous development and application of big data technology, digital technology continues to empower multiple industries to meet customer needs and improve service innovation capabilities through efficient integration of corporate resources with intelligence, connectivity, and analysis capabilities. Digital capabilities have promoted the generation of new forms of knowledge and provided the necessary channels for the realization of complex innovations [34]. In the era of digital information, the information platform is the base of information sharing. The information sharing of the platform can update information in a timely manner and stimulate more originalities and ideas, thereby promoting the achievement of service innovation projects among communicators and realizing the improvement of service innovation capability for all parties. With the continuous deepening of the application of digital technology for platform enterprises, data empowerment has penetrated deeply into the products and services of platform enterprises, fundamentally changing the product categories and service methods. Logistics platform enterprises, relying on digital information technology, can improve their information processing capabilities through enhancing the application of digital information technology and hence better catering customer needs, improving existing services, simulating product innovation, and realizing the improvement of the service innovation capabilities of logistics platform enterprises [34]. Therefore, the data empowerment of the logistics service platform has a positive effect on the realization of service innovation capabilities. Thus, the following hypothesis is proposed:

H1: data empowerment has a positive effect on the service innovation capabilities of logistics platform enterprises.

2.3. Data Empowerment and Value Co-creation. Value cocreation is the process of creating value and experience through interaction between enterprises and consumers
[35]. Gummesson and Mele have divided the value cocreation process into two aspects: interaction and resource integration [36]. The platform organization integrates into the multidirectional relationship of stakeholders and promotes value creation and value transfer through interaction and resource integration, achieving value co-creation among organizations. The integration of resources in the process of value co-creation can improve the value efficiency of oneself and the counterparty at the same time. Once the supplementary, redundant, or mixed resources in the value cocreation network are matched with each other among participants, the utility of resources will be maximized [37]. Therefore, the interactive cooperation and resource integration between users and enterprises are conducive to the realization of value co-creation.

Empowerment can realize value co-creation through cocreation activities such as interaction, cooperation, and resource integration, among different behavioral subjects (organizations, enterprises, consumers, etc.).

In indoor decoration platform enterprises, data empowerment makes customers change from passively accepting the design scheme to actively participate in the design process. At the same time, the design process balances the information asymmetry between customers and enterprises, which is conducive to promoting the value co-creation between customers and enterprises. In data-based tourism platform enterprises, represented by Didi, data empowerment is manifested in connection capabilities (people to people and people to objects), intelligence capabilities (user behavior perception), and analysis capabilities (information exchange), and the realization of data empowerment can promote the mutual cooperation and resource integration between both parties and realize the value co-creation of data-based travel platform enterprises. It can be seen that the data empowerment of platform enterprises can enhance the interaction between the enterprises and the customers and promote the integration of resources between the two parties, achieving mutual value. Since logistics platform enterprises have similar operating mechanisms and processes with platform enterprises, the data empowerment of logistics service platforms has a positive effect on the realization of value co-creation. Thus, the following hypotheses are proposed:

$\mathrm{H} 2$ : data empowerment has a positive effect on the interaction and cooperation of logistics platform enterprises.

H3: data empowerment has a positive effect on the resource integration of logistics platform enterprises.

\subsection{Value Co-creation and Service Innovation Capability.} Under the influence of value co-creation, enterprises enhance the openness of the service innovation platform, enlarge the scope of participation, and improve the voluntariness of participation and effort of the behavioral subjects in the process of service innovation, so as to enhance the interaction between the users and enterprises, which has a positive impact on the improvement of the service innovation capability of enterprises [38]. The participants corresponding to the platform enterprises with a higher 
degree of openness tend to be more active in participating in innovation activities, and the interaction and cooperation between enterprises and users are more frequent. The high degree of interactive cooperation is conducive to promoting platform enterprises to improve their service innovation capabilities. Platform openness offered vast opportunities for creating value that goes beyond enterprises' core competencies. Platform enterprises can make full use of the advantages of the platform architecture, integrate complementary assets in the ecosystem, and establish an ecological governance mechanism and a mutually beneficial co-creation mechanism, fully activating the potential of platform users and achieving collaborative innovation effects [39]. If enterprises can effectively integrate its internal resources, external resources, or both internal and external resources at the same time, it can gain competitive advantage to achieve value creation. Therefore, interactive cooperation and resource integration have a positive effect on the improvement of service innovation capabilities of platform enterprises. Thus, the following hypotheses are proposed:

$\mathrm{H} 4$ : interactive cooperation has a positive effect on the service innovation capability of logistics platform enterprises.

H5: resource integration has a positive effect on the service innovation capability of logistics platform enterprises.

2.5. The Mediating Effect of Value Co-creation. The Didi Chuxing platform, representing for the Internet big data platform, interacts and cooperates with other social networking platforms such as WeChat and Ganji.com through the application of data technology capabilities, to achieve a win-win situation for both parties. It has a strategic merger with Kuaidi and realizes the resource integration of mobile traveling platform, promoting the service innovation of platform enterprises. Platform enterprises can effectively use the data capabilities of the Internet to screen and process a wide range of information resources, break down the barriers of communication between enterprises and users through information resource integration, reduce communication costs, improve communication and decisionmaking efficiency, and realize the improvement of enterprises services innovation capabilities. Based on the effective use of big data, the logistics service platform enhances the interaction and cooperation with users, selects and integrates scattered information resources, reduces the communication cost of enterprises, enhances the management and decision-making capabilities of enterprises, and provides users with more suitable products and services. The service innovation capabilities of logistics platform enterprises have been improved. Therefore, interactive cooperation and resource integration play an intermediary role in the data empowerment and service innovation capabilities of logistics platform enterprises. Thus, the following hypotheses are proposed:

H6: interactive cooperation plays an intermediary role between data empowerment and logistics platform enterprise service innovation capabilities.
H7: resource integration plays an intermediary role between data empowerment and logistics platform enterprise service innovation capabilities.

2.6. The Moderating Effect of Environmental Dynamism. Environmental dynamism is manifested as changes in the market environment and market conditions, which can specifically be regarded as fluctuations in consumer demand in the market, adaptations in the marketing strategies of competitors, and the emergence of new technologies. When facing a complex market environment and uncertain changes, enterprises will adapt to the market environment in which they are located, and by examining the causes of environmental changes, they will improve the organization's change and innovation capabilities [40]. Environmental dynamism is manifested not only in the variability of the external market environment, but also in the variability of different stages of the enterprises' developing cycles. In different life stages of an enterprise in the development process, the impact of environmental dynamism on its service innovation capabilities will have different regulatory effects [41].

Under high environmental dynamism, the interactive cooperation between enterprises and consumers are more frequent. When the enterprise's own knowledge reserves fail to meet the requirements of service innovation capabilities, it can achieve value creation by learning external knowledge through interactive cooperation with consumers and suppliers and also enhance service innovation capabilities through the interactive cooperation between the two parties. Therefore, environmental dynamism has a positive moderating effect on knowledge sharing and service innovation capabilities [42]. In addition to positive adjustment, the moderating effect of environmental dynamism may also be U-shaped and inverted U-shaped [43]. When the environment becomes more turbulent, the impact on the enterprise is, in turn, uncertain or difficult to estimate. Since a considerable number of platform enterprises are still in the initial stage of corporate development, and limited by their own capabilities, high environmental dynamism may negatively regulate their service innovation capabilities.

With the development of platform enterprises, environmental volatility (market turbulence, competition turbulence, and technological turbulence) has become a norm in platform service industries. With the continuous improvement of environmental dynamism, when facing the intensified competition among enterprises and changes of user requirements, an enterprise can only better enhance its service innovation ability by satisfying the needs of users in a timely manner. Therefore, high environmental dynamism plays a moderating effect between interactive cooperation, resource integration, and platform enterprise service innovation capabilities. Thus, the following hypotheses are proposed:

H8: high environmental dynamism plays a positive regulatory effect between interactive cooperation and logistics platform enterprise service innovation capabilities. 
H9: high environmental dynamism plays a positive regulatory effect between resource integration and logistics platform enterprise service innovation capabilities.

In summary, the theoretical model constructed in this study is shown in Figure 1.

\section{Research Design}

3.1. Data Source. According to principles of typical representativeness, data collection, and research matching for logistics platform enterprises, this study selected logistics platform enterprises, Yunmanman, Lalamove, and Truck Alliance for research, and the respondents of the survey were managers, employees, drivers, and consumers of the platform enterprises. The items of the questionnaire adopt mature scale items that domestic and foreign scholars have and were measured using 7-point Likert scale. Based on the small-scale preinvestigation and testing, the scale was appropriately revised and adjusted in combination with the management practices of China's logistics platform enterprises.

160 questionnaires were distributed in the preinvestigation, and 82 of returned 143 were valid. The questionnaire response rate was $89.4 \%$, and the questionnaire validity rate was $57.3 \%$. According to the presurvey test results, the questionnaire items are revised and adjusted to form a formal questionnaire. The formal survey issued 838 questionnaires, of which 615 were returned and 360 were valid. The questionnaire response rate was $73.4 \%$ and the questionnaire validity rate was $58.5 \%$, which met the questionnaire collection indicators.

3.2. Variable Measurement. The measurement of data empowerment starts from the three aspects, intelligence ability, connection ability, and analysis ability, and it proposes 6 items for data empowerment. For the measurement of value co-creation, this research is conducted from two aspects: interactive cooperation and resource integration. The measurement of interactive cooperation is considered from three aspects. As logistics platform enterprises are dependent on the Internet, their operation patterns are mainly realized by connecting the two parties of the transaction. The existing fixed and basic resources are limited, and the development of the platform mainly depends on pioneering resources. The measurement of resource integration is considered from three items. Since the realization of service innovation capability is based on the enterprises' resource acquisition and the ability to capture and utilize external opportunities, the measurement of logistics platform enterprise service innovation capability is not much different from that of the enterprise service innovation capability. Therefore, this research measures the service innovation capability of logistics platform enterprises from four aspects. The existing logistics platform enterprises rely on the Internet, experiencing high volatile industry policies and markets, and inadequate consumer loyalty. Meanwhile, entry barriers of enterprises are relatively low, and competitors are prone to appear. The industry is highly competitive and various ways of competition are emerging. In addition, the Internet data platform where logistics platform enterprises are located presents fast and frequent technological development and updates. Therefore, this research measures environmental dynamism from three aspects: market volatility, competition intensity, and technological volatility. The results of measurement item are shown in Table 1.

\section{Data Analysis and Hypothesis Testing}

4.1. Reliability and Validity Analysis. Using Cronbach' $\alpha$ value to test the reliability of each variable, the data were analyzed with the help of Amos21.0 and Spss23.0, and the reliability and validity indicators of related measurement variables were obtained as shown in Table 2 . It shows that both the factor loading and Cronbach' $\alpha$ coefficient of each measured variable exceed 0.7 , indicating that the reliability of the scale is solid, while the KMO value of each variable is between 0.6 and 0.8 , which can be used for factor analysis.

With the help of Amos21.0 to conduct confirmatory factor analysis, the results show that the five-factor model has ideal fitting indexes, with high goodness of fit for the research model. Details are shown in Table 3 (index value).

4.2. Direct Effect Test. This study assumes that $\mathrm{H} 1$ believes data empowerment has a positive effect on service innovation capabilities. Therefore, based on the direct effect model M1, the relevant fitting index of the direct effect model is calculated by using the Amos21.0. It can be seen from Table 3 that the various fitting indicators of the direct effect model are relatively fine, indicating that the direct effect has a higher goodness of fit. The direct effect model M1 only considers the direct effect of data empowerment on service innovation capabilities, and further analysis and testing using Spss23.0 showed that the correlation coefficient between them was $0.846, p$ value was less than 0.001 , and the $t$ value was 30.075 . Considering the criterion that the $t$ value is greater than $1.96, R^{2}$ chge is close to 1 , and the Bootstrap interval test result does not contain 0 , it is shown that data empowerment has a positive effect on the service innovation ability, and hence the hypothesis $\mathrm{H} 1$ is verified. The test results are shown in Table 4.

4.3. Mediating Effect Test. For this research, the mediating effect of the model should be tested first, followed by the moderating effect of the model. For the test of the mediation model, this study separately verified the interactive cooperation and resource integration. On the basis of the mediation models M2 and M3, the relevant fitting index of mediating effect was analyzed by using Amos21.0. Detailed values are shown in Table 3 . It can be seen from Table 3 that mediating effect has a high goodness of fit. It can be seen from Table 4 that the mediating effect model M2 adds interactive cooperation to the direct effect model M1. It is found that the correlation coefficient $(\beta)$ of data empowerment to interactive cooperation is $0.828^{* * *}$, while the $t$ value is 27.908. The correlation coefficient of interactive 


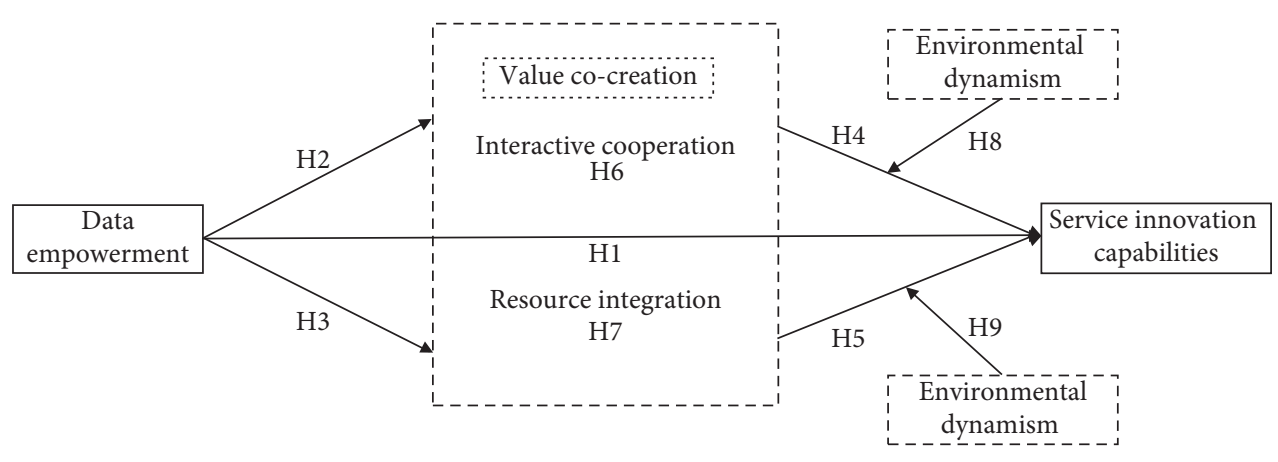

Figure 1: Theoretical model.

TABLE 1: Variable measurement item.

\begin{tabular}{|c|c|c|}
\hline \multicolumn{2}{|c|}{ Variable } & Measurement item \\
\hline \multirow{6}{*}{ Data empowerment } & Intelligence capability 1 & The platform has strong software development and vulnerability repair capabilities \\
\hline & Intelligence capability 2 & $\begin{array}{c}\text { The platform can flexibly classify products and provide corresponding products for } \\
\text { different customers }\end{array}$ \\
\hline & Connectivity capability 1 & The platform can provide other related product or service information for customers \\
\hline & Connectivity capability 2 & The platform interface or system can be accessed from other ports \\
\hline & Analysis capability 1 & $\begin{array}{c}\text { The platform can analyze business conditions and exploit emerging markets based on } \\
\text { the results }\end{array}$ \\
\hline & Analysis capability 2 & $\begin{array}{l}\text { The platform can combine the location of the user and match the order to the most } \\
\text { suitable driver through analysis }\end{array}$ \\
\hline \multirow{3}{*}{ Cooperative interaction } & $\begin{array}{l}\text { Cooperative interaction } \\
\qquad 1\end{array}$ & $\begin{array}{l}\text { During the operation of the platform, users should raise requests to the platform, } \\
\text { engage in dialogue at any time, and actively participate in interaction }\end{array}$ \\
\hline & $\begin{array}{l}\text { Cooperative interaction } \\
2\end{array}$ & $\begin{array}{l}\text { During the operation of the platform, the platform will conduct survey visits to users } \\
\text { and pass on relevant information }\end{array}$ \\
\hline & $\begin{array}{l}\text { Cooperative interaction } \\
3\end{array}$ & $\begin{array}{c}\text { During the operation, the platform allows registered drivers to interact with } \\
\text { consumers }\end{array}$ \\
\hline \multirow{3}{*}{ Resources integration } & Resources integration 1 & \multirow{3}{*}{$\begin{array}{l}\text { The platform can combine and utilize new resources } \\
\text { The platform can use innovative methods to combine resources to expand business } \\
\text { The platform can realize the creative combination of new resources and existing } \\
\text { resources }\end{array}$} \\
\hline & Resources integration 2 & \\
\hline & Resources integration 3 & \\
\hline
\end{tabular}

Services innovation capability 1

Services innovation capability 2

Services innovation capability

Services innovation capability 3

Services innovation capability 4

Environmental dynamism 1

Environmental dynamism
The platform setup service innovation process

The platform has the ability to respond to changing market conditions

The platform values the new service innovation projects

The platform uses new information technology to promote information sharing

The platform develops targeted marketing strategies to cater to different consumers

The industry that the platform is located in is highly competitive, with price wars or similar products appearing from time to time

The technology development and innovation of the industry that the platform is located in is fast cooperation on service innovation capability is $0.847^{* * *}$, and the $t$ value is 30.179 . According to the criteria that the $t$ value $>1.96$ and $p<0.001$, the hypotheses $\mathrm{H} 2$ and $\mathrm{H} 4$ are verified.

When interactive cooperation is involved in the relationship between data empowerment and service innovation capabilities, if the significant relationship between data empowerment and service innovation capabilities disappears, it can be assumed that interactive cooperation plays a completely mediating role between data empowerment and service innovation capabilities. If the relationship between data empowerment and service innovation capability is significant, it can be assumed that interactive cooperation plays a part of the mediating role between data empowerment and service innovation capability. The research results (from Figure 2 and Table 4) show that the correlation coefficient and $t$ value between data empowerment and service innovation ability are reduced from $\beta=0.846^{* * *}$ and $t=30.075$ to $\beta=0.461^{* * *}$ and $t=10.533$, respectively, and the 
TABLE 2: Reliability and validity analysis of measured variable.

\begin{tabular}{|c|c|c|c|c|}
\hline Variable & Item & Factor loading & Cronbach' $\alpha$ coefficient & KMO value \\
\hline \multirow{6}{*}{ Data empowerment } & Intelligence capability 1 & 0.811 & \multirow{6}{*}{0.873} & \multirow{6}{*}{0.868} \\
\hline & Intelligence capability 2 & 0.786 & & \\
\hline & Connectivity capability 1 & 0.791 & & \\
\hline & Connectivity capability 2 & 0.697 & & \\
\hline & Analysis capability 1 & 0.830 & & \\
\hline & Analysis capability 2 & 0.776 & & \\
\hline \multirow{3}{*}{ Cooperative interaction } & Cooperative interaction 1 & 0.877 & \multirow{3}{*}{0.813} & \multirow{3}{*}{0.671} \\
\hline & Cooperative interaction 2 & 0.802 & & \\
\hline & Cooperative interaction 3 & 0.880 & & \\
\hline \multirow{3}{*}{ Resources integration } & Resources integration 1 & 0.830 & \multirow{3}{*}{0.763} & \multirow{3}{*}{0.670} \\
\hline & Resources integration 2 & 0.767 & & \\
\hline & Resources integration 3 & 0.874 & & \\
\hline \multirow{4}{*}{ Services innovation capability } & Services innovation capability 1 & 0.824 & \multirow{4}{*}{0.831} & \multirow{4}{*}{0.776} \\
\hline & Services innovation capability 2 & 0.772 & & \\
\hline & Services innovation capability 3 & 0.831 & & \\
\hline & Services innovation capability 4 & 0.831 & & \\
\hline \multirow{3}{*}{ Environmental dynamism } & Environmental dynamism 1 & 0.889 & \multirow{3}{*}{0.801} & \multirow{3}{*}{0.673} \\
\hline & Environmental dynamism 2 & 0.769 & & \\
\hline & Environmental dynamism 3 & 0.878 & & \\
\hline
\end{tabular}

TABLE 3: Model fitting coefficient.

\begin{tabular}{lccccccccc}
\hline Fitting coefficient & $\chi^{2}$ & $\mathrm{~d} f$ & $\chi^{2} / \mathrm{d} f$ & RMR & RMSEA & GFI & AGFI & NFI & CFI \\
\hline Index value & 426.744 & 142 & 3.005 & 0.043 & 0.075 & 0.881 & 0.840 & 0.913 & 0.940 \\
Direct effect model & 79.15 & 28 & 2.827 & 0.035 & 0.071 & 0.957 & 0.915 & 0.961 & 0.974 \\
Mediating effect model & 315.1 & 99 & 3.18 & 0.042 & 0.078 & 0.897 & 0.859 & 0.920 & 0.943 \\
Criteria & & & $2 \sim 5$ & $<0.08$ & $<0.08$ & $\geq 0.90$ & $\geq 0.80$ & $\geq 0.90$ & $\geq 0.90$ \\
\hline
\end{tabular}

TABLE 4: Test result.

\begin{tabular}{|c|c|c|c|c|c|c|c|}
\hline \multirow{2}{*}{ Hypothesis } & \multirow{2}{*}{ Coeff. } & \multirow{2}{*}{$t$ value } & \multirow{2}{*}{$R^{2}$ chge } & \multirow{2}{*}{$F$ chge } & \multicolumn{2}{|c|}{ Bootstrap95\% (1000 times) } & \multirow{2}{*}{ Result } \\
\hline & & & & & Lower limit & Upper limit & \\
\hline $\mathrm{H} 1$ & $0.846^{* * *}$ & 30.075 & 0.716 & $904.485^{* * *}$ & 0.789 & 0.957 & Valid \\
\hline $\mathrm{H} 2$ & $0.828^{* * *}$ & 27.908 & 0.685 & $778.881^{* * *}$ & 0.813 & 0.984 & Valid \\
\hline $\mathrm{H} 4$ & $0.847^{* * *}$ & 30.179 & 0.718 & $910.769^{* * *}$ & 0.828 & 0.949 & Valid \\
\hline H6 & $0.466^{* * *}$ & 10.643 & 0.785 & $650.720^{* * *}$ & 0.283 & 0.588 & Valid \\
\hline $\mathrm{H} 3$ & $0.828^{* * *}$ & 27.921 & 0.685 & $779.577^{* * *}$ & 0.745 & 0.923 & Valid \\
\hline H5 & $0.869^{* * *}$ & 33.241 & 0.755 & $1104.982^{* * *}$ & 0.827 & 0.937 & Valid \\
\hline $\mathrm{H} 7$ & $0.535^{* * *}$ & 12.894 & 0.807 & $744.177^{* * *}$ & 0.382 & 0.686 & Valid \\
\hline
\end{tabular}

${ }^{* * *}$ indicates $p<0.001 ;{ }^{* *}$ indicates $p<0.01 ;{ }^{*}$ indicates $p<0.05$.

$F$ value is reduced from $904.485^{* * *}$ under the direct effect M1 to $650.720^{* * *}$. For the mediation effect of interactive cooperation, $\beta=0.466^{* * *}, t=10.643$, and $R^{2}$ chge is 0.785 . The results indicate that although the relationship between data empowerment and service innovation ability is weakened, the correlation between these two is still significant, and the $t$ value is reduced but still greater than 1.96. It indicates that interactive cooperation plays a part of the mediating role between data empowerment and service innovation capabilities. Hypothesis H6 is verified. In summary, after the direct effect M1 is added into interactive cooperation, the mediating effect of M2 is still significant. The above hypotheses of $\mathrm{H} 2, \mathrm{H} 4$, and $\mathrm{H} 6$ are all established.

After resource integration is added into the mediating effect model M3 on the basis of the direct effect M1 and tested by Spss23.0, the correlation coefficient of data empowerment to resource integration is $0.828^{* * *}$ and the $t$ value is 27.921 . The correlation coefficient of resource integration on service innovation capability is $0.869^{* * *}$, and the $t$ value is 33.241. According to the standard of $t$ value greater than 1.96 and $p<0.001$, hypotheses $\mathrm{H} 3$ and $\mathrm{H} 5$ have been verified. 


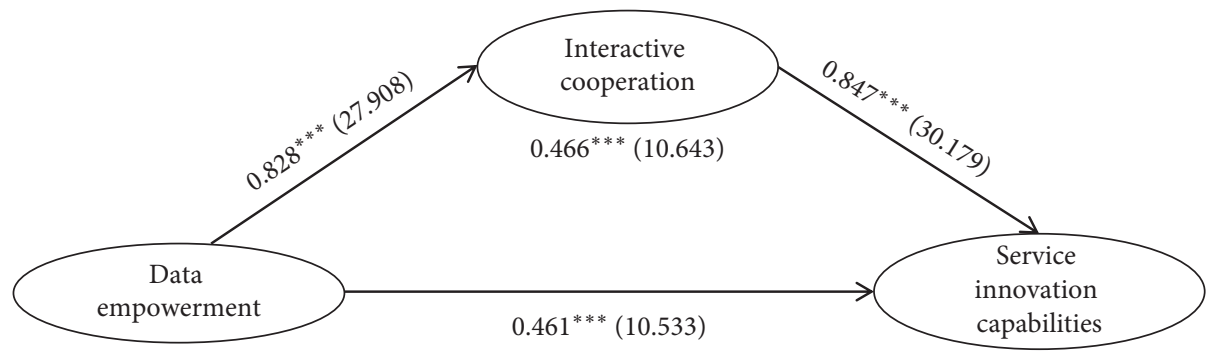

Figure 2: Mediating effect model M2.

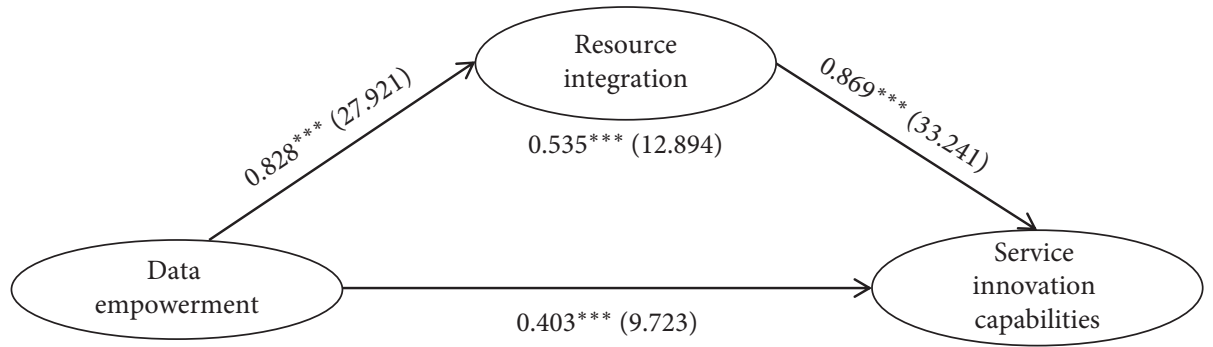

Figure 3: Mediating effect model M3.

TABle 5: Test result of the moderating effect of environmental dynamism.

\begin{tabular}{lccccc}
\hline Hypothesis & Path & $R^{2}$ chge & Coeff & $t$ value & Result \\
\hline H8 & Cooperative interaction $\times$ environmental dynamism $\longrightarrow$ services innovation capability & 0.003 & -0.341 & $2.046^{*}$ & Not valid \\
H9 & Resources integration $\times$ environmental dynamism $\longrightarrow$ services innovation capability & 0.001 & -0.260 & 1.630 & Not valid \\
\hline
\end{tabular}

When resource integration is involved in the relationship between data empowerment and service innovation capabilities, if the significant relationship between data empowerment and service innovation capabilities disappears, it can be considered that resource integration plays a completely intermediary role between data empowerment and service innovation capabilities. If the relationship between data empowerment and service innovation capability is significant, it can be considered that resource integration plays a part of the intermediary role between data empowerment and service innovation capability. According to the results (from Figure 3 and Table 4), the correlation coefficient and $t$ value between data empowerment and service innovation ability are reduced from $\beta=0.846^{* * *}$ and $t=30.075$ when the direct effect is M1 to $\beta=0.403^{* * *}$ and $t=9.723$, respectively, and the $\mathrm{F}$ value is reduced from $904.485^{* * *}$ to $744.177^{* * *}$. The mediating effect of interactive cooperation is $\beta=0.535^{* * *}, t=12.894$, and $R^{2}$ chge is 0.807 . The results show that although the relationship between data empowerment and service innovation capability is weakened, the correlation between the two is still significant. Although the $t$ value is reduced, it is still greater than 1.96, indicating that resource integration plays a part of the intermediary between data empowerment and service innovation capability effect, and hence Hypothesis H7 is verified. In summary, after the direct effect model M1 is added to resource integration, the test result of the mediation effect M3 is still significant. Hypotheses H3, H5, and $\mathrm{H} 7$ are all established. The hypothesis test results are shown in Table 4.
4.4. Moderating Effect Test. The moderating effect of this study is mediated moderation, which is to test the moderating role of environmental dynamism in interactive cooperation and service innovation capabilities, resource integration, and service innovation capabilities. The path coefficients of the moderating effects are obtained by Spss23.0 analysis, as shown in Table 5. From the results of the path coefficient, the interaction coefficient between the interaction of interactive cooperation and environmental dynamism and the service innovation capability is -0.341 , and the $t$ value is 2.046 . The interaction coefficient between the interaction of resource integration and environmental dynamism and the service innovation capability is -0.260 , and the $t$ value is 1.630 . Both interaction coefficients are negative, indicating that environmental dynamism failed to positively mediate the relationship between interactive cooperation and service innovation capabilities, resource integration, and service innovation capabilities and even inhibits the relationship between value cocreation and service innovation capabilities. Therefore, the hypotheses $\mathrm{H} 8$ and $\mathrm{H} 9$ have not been verified.

\section{Conclusions and Implications}

5.1. Conclusions. This research constructs a theoretical model that takes the intermediary variables of value cocreation and environmental dynamism as the moderating variables and divides the intermediary variables of value co-creation into interactive cooperation and resource integration. It discusses the mechanism of data 
empowerment on the service innovation capability of logistics platform enterprises and analyzes the moderating effect of environmental dynamism (market turbulence, competition turbulence, and technological turbulence) on value co-creation and service innovation capabilities in detail. Empirical analysis shows that data empowerment not only directly affects the service innovation capability of logistics platform enterprises but also indirectly affects service innovation capability through the intermediary effect of value co-creation (interactive cooperation and resource integration). In addition, environmental dynamism does not have a positive moderating effect on interaction and cooperation, resource integration, and service innovation capabilities but exhibits a certain inhibitory effect instead.

5.2. Implications for Practice. The research conclusion expands the theory of data empowerment and has important implications for the practice of logistics platform enterprises.

(1) Logistics platform enterprises should give full play to their intelligence, connectivity, and analysis capabilities to form their own data empowerment. Logistics platform enterprises should strengthen and make good use of their intelligence, connectivity, and analysis capabilities to keep abreast of data development trends and quickly find information conducive to their own development, so as to enhance their service innovation capabilities to gain a competitive advantage.

(2) It is empirically verified that data empowerment can affect service innovation capabilities by influencing value co-creation. This influence mechanism has an exemplary significance for improving the service innovation capabilities of logistics platform enterprises. Logistics platform enterprises can improve service innovation capabilities through effective interactive cooperation and resource integration with the help of data empowerment.

(3) When making decisions, logistics platform enterprises should consider not only their own capabilities and conditions, but also their actual tolerance to the external environment. With the rapid application and development of the Internet, the dynamism of the environment becomes more and more significant and becomes a variable factor that cannot be ignored in corporate decision-making. Under the high environmental dynamism, enterprises should consider their own capabilities, appropriately carry out or maintain interaction and cooperation with users, and focus their energy and resources on improving their own capabilities. Enterprises should create and develop their own logistics resources, meet user demands in a timely and efficient manner, and enhance the service innovation capabilities of platform enterprises.
5.3. Limitations and Future Research. As with most researches, the design of this research is subject to limitations, which opens up opportunities for future research. Firstly, we collect data from specific logistics platform enterprises; there may be difference for the applicability of the model to platform enterprises in other industries, and further research should extend our model to other industries. Secondly, the informant bias could be a concern, as only managers, employees, drivers, and consumers completed the survey. Future research could attempt to avoid such concerns by recruiting multiple informants, e.g., senior managers. Finally, our research is cross-sectional, which limits the test of the causal inferences for platform enterprise data empowerment and service innovation capabilities. Due to the fact that practicing platform enterprise data empowerment and developing enterprise service innovation capabilities require enterprises to continuously create bundles of new resources and knowledge, future research should examine the coevolution between data empowerment and service innovation capabilities with a panel data research.

\section{Data Availability}

The data used to support the findings of this study are available from the corresponding author upon request.

\section{Conflicts of Interest}

The authors declare there are no conflicts of interest regarding the publication of this paper.

\section{Acknowledgments}

This research was financially supported by the National Natural Science Foundation of China (no. 71974039).

\section{References}

[1] A. Tiwana, "Evolutionary competition in platform ecosystems," Information Systems Research, vol. 26, no. 2, pp. 266-281, 2015.

[2] D. S. Evans, "Attention platforms, the value of content, and public policy," Review of Industrial Organization, vol. 54, no. 4, pp. 775-792, 2019.

[3] A. T. Johnsen, N. B. Eskildsen, T. G. Thomsen, M. Grønvold, L. Ross, and C. R. Jørgensen, "Conceptualizing patient empowerment in cancer follow-up by combining theory and qualitative data," Acta Oncologica, vol. 56, no. 2, pp. 232-238, 2017.

[4] C. K. H. Wong, C. L. K. Lam, E. Y. F. Wan et al., "Evaluation of patient-reported outcomes data in structured diabetes education intervention: 2-year follow-up data of patient empowerment programme," Endocrine, vol. 54, no. 2, pp. 422-432, 2016

[5] J. Heckert and M. S. Fabic, "Improving data concerning women's empowerment in sub-saharan africa," Studies in Family Planning, vol. 44, no. 3, pp. 319-344, 2013.

[6] P. Pierre and S. J. Floyd, "Refining the conceptualization and measurement of women's empowerment in sub-saharan africa using data from the 2013 nigerian demographic and 
health survey," Social Indicators Research, vol. 140, no. 2, pp. 777-793, 2018.

[7] M. W. Alsem, M. Verhoef, J. Braakman et al., "Parental empowerment in paediatric rehabilitation: exploring the role of a digital tool to help parents prepare for consultation with a physician," Child Care Health, vol. 45, no. 12, pp. 623-636, 2019.

[8] M. N. Hossain, M. S. Talukder, M. R. Hoque, and Y. Bao, "The use of open government data to citizen empowerment: an empirical validation of a proposed model," Foresight, vol. 20, no. 6, pp. 665-680, 2018.

[9] Y. Tim, S. L. Pan, S. Bahri, and A. Fauzi, "Digitally enabled affordances for community-driven environmental movement in rural Malaysia," Information Systems Journal, vol. 28, no. 1, pp. $48-75,2017$.

[10] B. Akkoyunlu and A. Yilmaz, "Prospective teachers' digital empowerment and their information literacy self-efficacy," Eurasian Journal of Educational Research, vol. 44, no. 11, pp. 33-50, 2011.

[11] C. Costa, M. Murphy, and A. L. Pereira, "Higher education students' experiences of digital learning and (dis) empowerment," Australasian Journal of Educational Technology, vol. 34, no. 3, pp. 140-152, 2018.

[12] D. J. Teece, G. Pisano, and A. Shuen, "Dynamic capabilities and strategic management," Strategic Management Journal, vol. 18, no. 7, pp. 509-533, 1997.

[13] J. B. Barney, D. J. Ketchen Jr., and M. Wright, "The future of resource-based theory: revitalization or decline?" Journal of Management, vol. 37, no. 5, pp. 1299-1315, 2011.

[14] S. Lenka, V. Parida, and J. Wincent, "Digitalization capabilities as enablers of value co-creation in servitizing firms," Psychology \& Marketing, vol. 34, no. 1, pp. 92-100, 2017.

[15] L. Z. Song, M. Song, and C. A. Di Benedetto, "A staged service innovation model," Decision Sciences, vol. 40, no. 3, pp. 571-599, 2009.

[16] B. B. Flynn, B. Huo, and X. Zhao, "The impact of supply chain integration on performance: a contingency and configuration approach," Journal of Operations Management, vol. 28, no. 1, pp. 58-71, 2010.

[17] L. A. Bettencourt, S. W. Brown, and N. J. Sirianni, "The secret to true service innovation," Business Horizons, vol. 56, no. 1, pp. 13-22, 2013.

[18] P. den Hertog, W. van der Aa, and M. W. de Jong, "Capabilities for managing service innovation: towards a conceptual framework," Journal of Service Management, vol. 21, no. 4, pp. 490-514, 2010.

[19] D. Kindström, C. Kowalkowski, and E. Sandberg, "Enabling service innovation: a dynamic capabilities approach," Journal of Business Research, vol. 66, no. 8, pp. 1063-1073, 2013.

[20] N. Evers, S. Andersson, and M. Hannibal, "Stakeholders and marketing capabilities in international new ventures: evidence from Ireland, Sweden, and Denmark," Journal of International Marketing, vol. 20, no. 4, pp. 46-71, 2012.

[21] A. Ganguly, A. Talukdar, and D. Chatterjee, "Evaluating the role of social capital, tacit knowledge sharing, knowledge quality and reciprocity in determining innovation capability of an organization," Journal of Knowledge Management, vol. 23, no. 6, pp. 1105-1135, 2019.

[22] C. A. Lengnick-Hall and R. J. Griffith, "Evidence-based versus tinkerable knowledge as strategic assets: a new perspective on the interplay between innovation and application," Journal of Engineering and Technology Management, vol. 28, no. 3, pp. 147-167, 2011.
[23] L. J. Menor and A. V. Roth, "New service development competence in retail banking: construct development and measurement validation," Journal of Operations Management, vol. 25, no. 8, pp. 825-846, 2007.

[24] T. Bauer and K. Borodako, "Trade show innovations - organizers implementation of the new service development process," Journal of Hospitality and Tourism Management, vol. 41, no. 12, pp. 197-207, 2019.

[25] G. Akman and C. Yilmaz, "Innovative capability, innovation strategy and market orientation: an empirical analysis in Turkish software industry," International Journal of Innovation Management, vol. 12, no. 1, pp. 69-111, 2008.

[26] N. Lindberg and F. Nordin, "From products to services and back again: towards a new service procurement logic," Industrial Marketing Management, vol. 37, no. 3, pp. 292-300, 2008.

[27] D. Kafetzopoulos, K. Gotzamani, and V. Gkana, "Relationship between quality management, innovation and competitiveness. evidence from Greek companies," Journal of Manufacturing Technology Management, vol. 26, no. 8, pp. 1177-1200, 2015.

[28] H. Perks, T. Gruber, and B. Edvardsson, "Co-creation in radical service innovation: a systematic analysis of microlevel processes," Journal of Product Innovation Management, vol. 29, no. 6, pp. 935-951, 2012.

[29] C. Jaw, J.-Y. Lo, and Y.-H. Lin, "The determinants of new service development: service characteristics, market orientation, and actualizing innovation effort," Technovation, vol. 30, no. 4, pp. 265-277, 2010.

[30] C. M. Wallenburg, "Innovation in logistics outsourcing relationships: proactive improvement by logistics service providers as a driver of customer loyalty," Journal of Supply Chain Management, vol. 45, no. 2, pp. 75-93, 2009.

[31] Y. C. Chen, P. C. Li, and K. R. Evans, "Effects of interaction and entrepreneurial orientation on organizational performance: insights into market driven and market driving," Industrial Marketing Management, vol. 41, no. 6, pp. 10191034, 2012.

[32] S. J. Hogan, G. N. Soutar, J. R. McColl-Kennedy, and J. C. Sweeney, "Reconceptualizing professional service firm innovation capability: scale development," Industrial Marketing Management, vol. 40, no. 8, pp. 1264-1273, 2011.

[33] Cornell Empowerment Group, "Empowerment and family support," Networking Bulletin, vol. 1, no. 2, pp. 1-23, 1989.

[34] D. Dougherty and D. D. Dunne, "Digital science and knowledge boundaries in complex innovation," Organization Science, vol. 23, no. 5, pp. 1467-1484, 2012.

[35] C. K. Prahalad and V. Ramaswamy, "Co-creation experiences: the next practice in value creation," Journal of Interactive Marketing, vol. 18, no. 3, pp. 5-14, 2004.

[36] E. Gummesson and C. Mele, "Marketing as value co-creation through network interaction and resource integration," Journal of Business Market Management, vol. 4, no. 4, pp. 181-198, 2010.

[37] C. Neghina, M. C. J. Caniëls, J. M. M. Bloemer, and M. J. H. van Birgelen, "Value cocreation in service interactions," Marketing Theory, vol. 15, no. 2, pp. 221-242, 2015.

[38] N. O. Ommen, M. Blut, C. Backhaus, and D. M. Woisetschläger, "Toward a better understanding of stakeholder participation in the service innovation process: more than one path to success," Journal of Business Research, vol. 69, no. 7, pp. 2409-2416, 2016.

[39] W. Fu, Q. Wang, and X. Zhao, "Platform-based service innovation and system design: a literature review," Industrial 
Management \& Data Systems, vol. 118, no. 5, pp. 946-974, 2018.

[40] I. P. Mccarthy, T. B. Lawrence, B. Wixted, and B. R. Gordon, "A multidimensional conceptualization of environmental velocity," Academy of Management Review, vol. 35, no. 4, pp. 604-626, 2010.

[41] C. Dibrell, J. Craig, and E. Hansen, "Natural environment, market orientation, and firm innovativeness: an organizational life cycle perspective," Journal of Small Business Management, vol. 49, no. 3, pp. 467-489, 2011.

[42] Z. Yang, V. T. Nguyen, and P. B. Le, "Knowledge sharing serves as a mediator between collaborative culture and innovation capability: an empirical research," Journal of Business \& Industrial Marketing, vol. 33, no. 7, pp. 958-969, 2018.

[43] G. Li, W. Yaru, and S. Feng, "A study on the relationship among strategic orientation, absorption capacity and service innovation performance: the regulatory role of environmental uncertainty," Journal of North China University of Water Resources and Electric Power (Social Science Edition), vol. 35, no. 5, pp. 24-32, 2019. 